\title{
A COMPARATIVE STUDY ON USES OF SUPRATARSAL TRIAMCINOLONE INJECTION, TOPICAL STEROIDS AND CYCLOSPORINE IN CASES OF REFRACTORY VERNAL KERATOCONJUNCTIVITIS
}

\author{
Smita Anand ${ }^{1}$, Shobhit Varma 2 , Vidya Bhushan Sinha ${ }^{3}$
}

${ }_{1}^{1}$ Senior Resident, Department of Ophthalmology, Rajendra Institute of Medical Sciences, Ranchi. ${ }^{2} J u n i o r R e s i d e n t$, Department of Ophthalmology, Rajendra Institute of Medical Sciences, Ranchi. ${ }_{3}^{3} \mathrm{HOD}$, Department of Ophthalmology, Rajendra Institute of Medical Sciences, Ranchi.

\section{ABSTRACT}

\section{BACKGROUND}

The aim is to study and compare supratarsal triamcinolone injection efficacy in respect to conventional modes of topical steroids \& cyclosporine in cases of refractory VKC.

\section{MATERIALS AND METHODS}

78 patients of refractory VKC were randomly distributed in 3 groups of 26 patients each. Topical difluprednate was given in group I, $0.4 \mathrm{mg}$ triamcinolone acetonide was injected in supratarsal area in group II while $0.1 \%$ cyclosporine/Tacrolimus was given in Group III.

\section{RESULTS}

$51(65 \%)$ were male while 27 (35\%) were female with mean age group of $12.2 \pm 3.5$ years (Range -7 to 21 years). In group I, large papillae resolved in only 20 (77\%) patients of the group while active shield ulcer resolved in 18 (69\%) patients. In group II patients, large papillae and active shield ulcer showed marked improvement in 25 (97\%) patients. There was significant difference as compared to topical steroids in respect to these signs. In group III patients, symptoms and signs improvement was less when compared to others. Recurrence was seen in both topical steroids and injectable triamcinolone after 3 months in almost $20-30 \%$ patients. In cyclosporine treated group, this was as high as $50-60 \%$ after 3 months.

\section{CONCLUSION}

Supratarsal injection has better patient compliance and significant improvement in signs over topical steroids although recurrence is almost similar. Prompt IOP monitoring is very important. Cyclosporine can be used in maintenance therapy because of its less side effects though its efficacy is far less than other 2 modes.

\section{KEYWORDS}

Vernal Keratoconjunctivitis, Supratarsal Triamcinolone Injection.

HOW TO CITE THIS ARTICLE: Anand S, Varma S, Sinha VB. A comparative study on uses of supratarsal triamcinolone injection, topical steroids and cyclosporine in cases of refractory vernal keratoconjunctivitis. J. Evolution Med. Dent. Sci. 2017;6(14):11291132, DOI: $10.14260 /$ Jemds/2017/245

\section{BACKGROUND}

Ninety percent of ocular allergies are in the form of seasonal and perennial allergic conjunctivitis. While allergic conjunctivitis is a fairly mild disease, it can result in considerable costs in terms of lost productivity and decreases in quality of life. Limited epidemiological data of vernal keratoconjunctivitis is available in India.

Vernal, derived from the Greek meaning occurring in the spring, is a rare, serious form of ocular allergy. The disease characteristics include a predilection for warm rather than cold climates, a frequent family and personal history of atopic disease, a higher than 2:1 frequency in males over females, and an early onset with $80 \%$ of patients below 14 years of age, ${ }^{1}$ with remission in late teens.

Financial or Other, Competing Interest: None.

Submission 07-01-2017, Peer Review 01-02-2017,

Acceptance 06-02-2017, Published 16-02-2017.

Corresponding Author:

Dr. Smita Anand,

Senior Resident,

Department of Ophthalmology,

Rajendra Institute of Medical Sciences,

Ranchi-834009, Jharkhand.

E-mail: smita.anand2001@gmail.com

DOI: $10.14260 /$ jemds $/ 2017 / 245$

\section{(c) (i) $(5)$}

Characterised by ptosis, ropy mucous discharge, photophobia, large, non-uniform cobblestone papillae, Horner-Trantas dots, limbal nodules, neovascularisation, corneal shield ulcers, and itching. The common and often debilitating symptoms of VKC are itching, photophobia, and pain. $^{2}$

Patients who take anti-allergic medications systemically or nasally need to be asked specifically about eye symptoms, since it is estimated that $90 \%$ of patients with allergic rhinitis have ocular symptoms as well. ${ }^{3}$

The large cobblestones of the upper tarsal plate are pathognomonic for this disease, but they do require lid eversion to be identified. Thus, this is an indispensable component of the external ophthalmic examination. These cobbles differ from those in giant papillary conjunctivitis by being dramatically larger in height and breadth and varying in shape in a different pattern than the homogeneous cobbles seen in GPC or in the follicles in viral conjunctivitis. Scarring is not present, regardless of the number of years that VKC has been present. If scarring exists, it is more suggestive of the Arlt's lines found in trachoma. The development of ptosis is related to the presence of keratitis and photophobia, producing a protective response. Additionally, it can be caused by the increased bulk of upper tarsal conjunctiva or myositis of the levator muscle, suggestion to the patient is to 
limit digital manipulation and knuckle rubbing of the eye as much as possible, as this has been shown to cause mechanical release of mast cell mediators.

Pattern of VKC in the Indian subcontinent is essentially similar to pattern in other tropical countries which is predominantly a mixed form of disease (72\%) with a significant no. of patients having a chronic perennial form (36\%) and lesser association with atopy or systemic allergies as compared to patients in temperate zones. ${ }^{4}$

Topical steroids and cyclosporine or tacrolimus are main modalities of preventing recurrences and giving symptomatic relief to the refractory VKC cases. Cooperative patients can be offered an alternative to topical delivery that avoids the problem of continuing self-medication: supratarsal injection of corticosteroid. The supratarsal subconjunctival space is located superior to the upper border of the superior tarsus and is most easily reached by everting the upper eyelid. This space is free of the subepithelial adhesions that bind the superior palpebral conjunctiva to the tarsal plate. Monitoring of intraocular pressure is mandatory, as corticosteroidinduced pressure spikes are possible. ${ }^{5}$

\section{MATERIALS AND METHODS}

This study was conducted during the period of January 2015 to August 2016 in RIO, RIMS, Ranchi which is the nodal centre of ophthalmology in Jharkhand. Seventy Eight patients were included in the study with severe refractory VKC on the basis of symptoms, signs and medication history.

Symptoms like severe itching and thick ropy discharge, photophobia, and lacrimation that interfered with their daily activity were considered in refractory cases. Inclusion criteria being large cobblestone papillae, Horner-Trantas dots with any of these [active shield ulcer, macroerosion, limbal stem cell deficiency with conjunctivisation, coarse punctate epithelial keratitis (PEK), conjunctival granuloma, limbal pannus indicating severe annular limbal inflammation] ${ }^{4}$. Exclusion criteria was any VKC condition not lying in chronic recurrent criteria which is occurrence less than 4 times per year, patient having inflammation free interval of greater than $2-3$ months per year. Raised intraocular pressure (IOP) and patients on anti-glaucoma medications were also excluded.

Grading of both eyes were done separately. Large papillae with no corneal or limbal involvement were put in mild category because it may be inactive and not causing corneal erosion. Periodicity of symptoms and signs was an important criteria.

Out of 78 patients, 26 patients were kept on topical steroids, 26 patients being given supratarsal steroid injections while rest 26 were kept on $0.1 \%$ cyclosporine eye drops. Informed consent was taken after complete description of the procedure and its purpose to the patient and their parents.

In group I patients, topical difluprednate was given with tapering done weekly for one month. In group II, 4\% Xylocaine was instilled in the eye and one minute later the upper lid was gently reverted, and with a cotton-tipped applicator, soaked with $4 \%$ Xylocaine. Then, $0.4 \mathrm{~mL}$ of triamcinolone acetonide (20 mg drug) was injected in potential space between conjunctiva and Muller's muscle, 0.5-1 mm superior to upper edge of tarsus with 27 gauge needle. (Fig I) Lid returned to normal position and all previous topical medications were discontinued. 6 Topical antibiotics were given for a week post injection. In group III, patients were kept on $0.1 \%$ cyclosporine/tacrolimus for 2 months.

Patients were followed-up in the first and fourth week after injection, and symptoms and signs were evaluated and results recorded with monitoring of IOP. Follow-up was continued in 3, 6, 9 months in respect to patients arrival at our hospital in all 3 treatment groups.

\section{RESULTS}

Out of 78 patients with refractory VKC, 51 (65\%) were male while $27(35 \%)$ were female with mean age group of $12.2 \pm$ 3.5 years (Range-7 to 21 years). Randomised distribution was done to avoid any bias.

As explained in Table I, in group I all symptoms resolved on 1 month follow-up. Limbal pannus and Horner-Trantas dots healed in all patients but large papillae resolved in only $20(77 \%)$ patients of the group while active shield ulcer in 18 (69\%) patients.

In group II patients being given supratarsal triamcinolone all symptoms and signs improvement were similar to topical steroids except that large papillae and active shield ulcer showed marked improvement in 25 (97\%) of patients. There was significant difference as compared to topical steroids in respect to those signs.

Raised IOP was seen in $2(6 \%)$ patients on 1 week followup and further injections were discontinued in them although the patients showed remarkable improvement in signs and symptoms. Three patients (9\%) reported with mild redness on next day of injection, which resolved spontaneously.

In group III patients, symptoms such as severe itching, ropy discharge and photophobia showed improvement but it was not comparable to topical or injectable depot steroid. While resolution of large papillae 1 (3\%); Horner-Trantas spots $8(30 \%)$ and active shield ulcer healing was seen in none of the patient on follow-up.

In Table II, it is elaborated that recurrence was seen in both topical steroids and injectable triamcinolone after 3 months in almost 20-30 \% patients. In cyclosporine treated group, this was as high as $50-60 \%$ after 3 months. Supratarsal triamcinolone injection had best patient compliance though prompt IOP monitoring was a major shortcoming post injection. Prolonged use of potent topical steroid has a major side effect in cataract, thus it needs to be regularly evaluated.

\section{No. of Patients (Percentage)}

\begin{tabular}{|c|c|c|c|}
\hline \multirow{2}{*}{$\begin{array}{c}\text { Symptoms \& } \\
\text { Signs }\end{array}$} & $\begin{array}{c}\text { Topical Steroids } \\
\text { (Difluprednate) }\end{array}$ & $\begin{array}{c}\text { Supratarsal } \\
\text { triamcinolone }\end{array}$ & $\begin{array}{c}\text { Topical 0.1\% } \\
\text { Cyclosporine } \\
\text { / Tacrolimus }\end{array}$ \\
\cline { 2 - 4 } & Group I & Group II & Group III \\
\hline $\begin{array}{c}\text { Severe } \\
\text { itching }\end{array}$ & $26(100 \%)$ & $26(100 \%)$ & $15(57 \%)$ \\
\hline $\begin{array}{c}\text { Ropy } \\
\text { Discharge }\end{array}$ & $26(100 \%)$ & $26(100 \%)$ & $13(50 \%)$ \\
\hline Photophobia & $26(100 \%)$ & $26(100 \%)$ & $20(77 \%)$ \\
\hline $\begin{array}{c}\text { Large } \\
\text { papillae }\end{array}$ & $20(77 \%)$ & $25(97 \%)$ & $1(3 \%)$ \\
\hline $\begin{array}{c}\text { Horner } \\
\text { Trantas dots }\end{array}$ & $26(100 \%)$ & $26(100 \%)$ & $8(30 \%)$ \\
\hline $\begin{array}{c}\text { Active shield } \\
\text { ulcer }\end{array}$ & $18(69 \%)$ & $25(96 \%)$ & $0(3 \%)$ \\
\hline $\begin{array}{c}\text { Limbal } \\
\text { Pannus }\end{array}$ & $26(100 \%)$ & $26(100 \%)$ & $10(30 \%)$ \\
\hline \multicolumn{4}{|c|}{$\begin{array}{c}\text { Table I. Improvement of Symptoms } \\
\text { and Signs after 1-month Follow-up }\end{array}$} \\
\hline \multicolumn{4}{|c|}{} \\
\hline
\end{tabular}




\begin{tabular}{|c|c|c|c|}
\hline & $\begin{array}{c}\text { Topical Steroids } \\
\text { (Difluprednate) }\end{array}$ & $\begin{array}{c}\text { Supratarsal } \\
\text { triamcinolone }\end{array}$ & $\begin{array}{c}\text { Topical 0.1\% } \\
\text { Cyclosporine } \\
\text { /Tacrolimus }\end{array}$ \\
\hline Compliance & + & +++ & ++ \\
\hline Recurrence & + & + & +++ \\
\hline $\begin{array}{c}\text { IOP } \\
\text { Monitoring }\end{array}$ & + & +++ & - \\
\hline $\begin{array}{c}\text { Cataract } \\
\text { complication } \\
\text { (prolong use) }\end{array}$ & +++ & + & - \\
\hline \multicolumn{3}{|c|}{ Table II. Comparative Analysis } \\
\hline \multicolumn{4}{|c|}{} \\
\hline
\end{tabular}

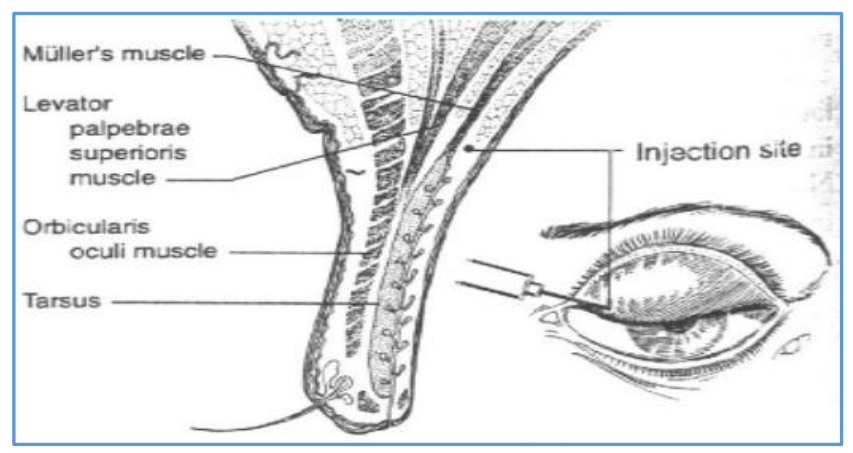

Figure I. Site of Supratarsal Injection ${ }^{8}$

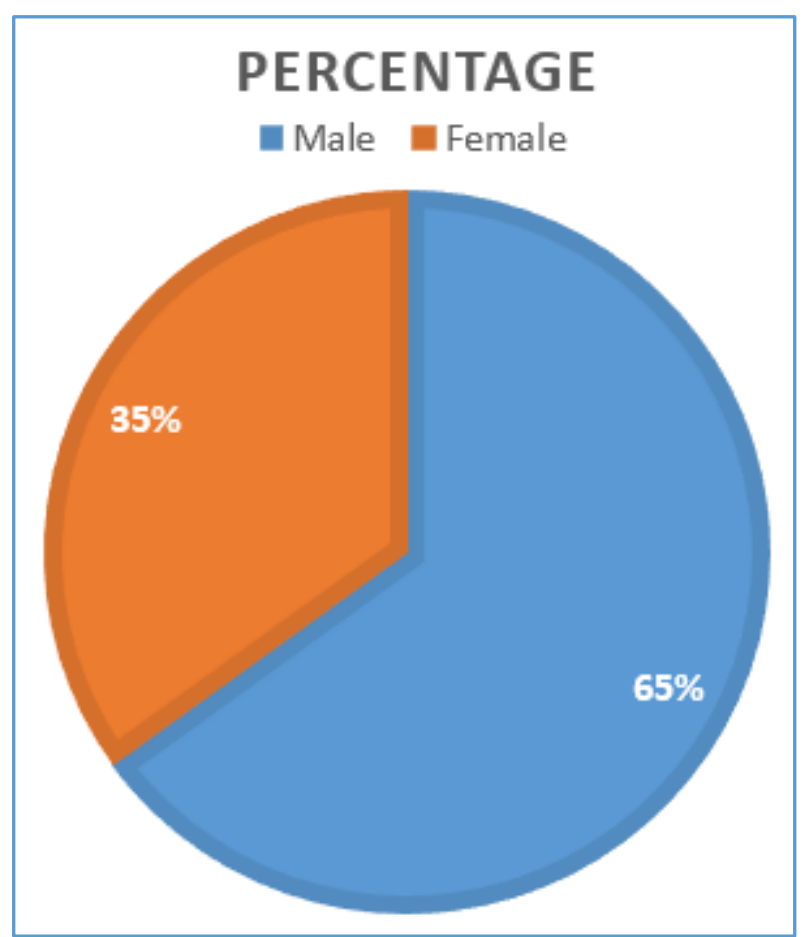

Figure II. Sex Distribution

\section{DISCUSSION}

While VKC has wide geographical distribution, it is common in the tropics, including Mediterranean area, Balkans, North and South Africa, and the Indian subcontinent. Some patients develop severe recalcitrant disease which is unresponsive to standard treatment. ${ }^{7}$ These patients develop disease-related and/or iatrogenic complications with irreparable ocular morbidity and even blindness. Many patients with advanced VKC remain markedly symptomatic and debilitated despite the most aggressive medical management.
Such cases pose a great challenge. Surgical excision and cryotherapy of large papillae have been considered and abandoned due to extensive scarring. ${ }^{8}$

This comparative study showed that triamcinolone acetonide injection in supratarsal area can relieve signs and symptoms. Douglas et al showed that they had no recurrence of VKC after short or intermediate acting steroids injection in supratarsal areas. This difference may be due to quality of medication and immunologic status of patients.

In our study, after 18 months of follow-up, we had 6\% patients with raised IOP which was also mentioned in Douglas et al report having intraocular pressure rise in $9 \%$ of the cases after steroid injection. The mean age of our patients was 12.2 \pm 3.5 years (Range 7-21 years); in other studies, the mean was 12 years. ${ }^{9}$ The ratio of male to female was $2: 1$ in our study which was in accordance with worldwide data. (Fig. II).

Supratarsal injection of corticosteroids provides initial symptomatic relief by reducing the inflammation locally. Intralesional depot steroid injections do not raise significant blood cortisol levels to exert systemic anti-inflammatory activity or cause remission of inflammation at another site in the body. ${ }^{10,11}$ In our study, the initial response to treatment was consistent with reports of Holsclaw et al and Saini et al. They also observed maximal reduction in size of papillae in 2 weeks and healing of shield ulcers in 3 weeks. ${ }^{11}$

In all of the studies, symptoms and clinical signs of VKC were the same and in its pathogenesis, multiple factors such as IgE, IgG, cell-mediated immunity, eosinophils, and basophils were involved. ${ }^{12}$

\section{CONCLUSION}

In summary, we used supratarsal injection of triamcinolone acetonide in patients with severe refractory VKC applying topical anaesthesia.

The procedure is usually well tolerated even in young children; it provides prompt symptomatic relief in all patients, and has low recurrence rate. The high rate of clinical response with less complications and yet easy method with excellent compliance of patients over other modalities leads us to suggest that this therapeutic modality is an effective and safe method for treatment of refractory VKC.

\section{Acknowledgement}

This study was substantially supported by all faculties and postgraduate trainees in Regional Institute of Ophthalmology, Ranchi, India.

\section{REFERENCES}

[1] Allansmith MR, Ross RN. Ocular allergy and mast cell stabilizers. Surv Ophthalmol 1986;30(4):229-44.

[2] Jones BR. Vernal keratitis. Trans Ophthalmol Soc UK 1961;81:215-28.

[3] Berger W, Abelson MB, Gomes PJ, et al. Effects of adjuvant therapy with $0.1 \%$ olopatadine hydrochloride ophthalmic solution on quality of life in patients with allergic rhinitis using systemic or nasal therapy. Ann Allergy Asthma Immunol 2005;95(4):361-71. 
[4] Gokhale NS. Systematic approach to managing vernal keratoconjunctivitis in clinical practice: severity grading system and treatment algorithm. Indian J Ophthalmol 2016;64(2):145-8.

[5] Diagnosis and management of immune related disorders of the external eye. In: External disease and cornea. American academy of ophthalmology 20142015. s8.c7.171-201.

[6] Singh S, Pal V, Dhull CS. Supratarsal injection of corticosteroids in the treatment of refractory vernal keratoconjunctivitis. Indian J Ophthalmol 2001;49(4):241-5.

[7] Holsclaw DS, Witcher JP, Wong IG, et al. Supratarsal injection of corticosteroid in the treatment of refractory vernal keratoconjunctivitis. Am J Ophthalmol 1996;121(3):243-9.

[8] Gunduz K, Ucakhan O, Budak K, et al. Efficacy of lodoxamide $0.1 \%$ versus $\mathrm{N}$-acetyl aspartylglutamic acid 6\% ophthalmic solutions in patients with vernal keratoconjunctivitis. Ophthalmic Res 1996;28:80-7.
[9] Bagheri A, Khaksar M. Epidemiology of vernal keratoconjunctivitis in Kashan [in Persian]. Feiz 1996;2:34-52.

[10] Guzzo CA, Lazarus GS, Werh VP. Dermatologic pharmacology. In: Hurdman JG, Limbird LE, Motinoff PB, et al. eds. Goodman and Gilman's pharmacological basis of therapeutics. New York: McGraw Hill 1996; p. 1597.

[11] Saini JS, Gupta A, Pandey SK, et al. Efficacy of supratarsal dexamethasone versus triamcinolone injection in recalcitrant vernal keratoconjunctivitis. Acta Ophthalmol Scand 1999;77(5):515-8.

[12] Allan Smith MR. Vernal conjunctivitis: Duane's clinical ophthalmology. Vol 4. $2^{\text {nd }}$ edn. Philadelphia: Lippincott-Raven 1991:1-8. 